\title{
Editors' Introduction: Linguistics, Translation and Teaching in LSP
}

\author{
Mary Frances Litzler ${ }^{1}$ \\ Universidad de Alcalá
}

\author{
Elena Martín Monje \\ Universidad Nacional de Educacion a Distancia
}

This special issue of Revista de Lenguas para Fines Especificos takes a broad view of the field of languages for specific purposes (LSP) that includes the characteristics of language in specific areas of study, adaptation during the translation process and the teaching of specialized courses. The seven papers in the present issue of the journal discuss innovative practices and findings in linguistics, teaching and translation in a variety of fields, such as engineering, medicine, business and education. $^{2}$

The first four papers deal with different aspects of teaching LSP in a foreign language setting. In the first one Alejandro Curado Fuentes discusses the use of Data Driven Learning (DDL) for the teaching of grammar in English classes in a dual degree program in Business and Tourism in Extremadura, Spain. In his study, one group of students used concordancing to examine grammatical context while another group of students used a corpus-informed textbook. When the two groups took a grammar test, the DDL group obtained slightly better results than the group

\footnotetext{
${ }^{1}$ Corresponding author - Departamento de Filología Moderna, Calle Trinidad, 3, 28801 Alcalá de Henares (Madrid) Spain.

E-mail: mf.litz@uah.es.

${ }^{2}$ The editors would like to express their appreciation to the reviewers who collaborated in the selection and improvement of the articles for this edition. Their help has been fundamental in putting it together.
} 
that had used a textbook, suggesting that teacher assisted discovery of grammar through corpus work is worth fostering in the context of English for Specific Purposes settings.

Marián Amengual Pizarro presents a study on motivation of students learning English in an Engineering program on the Balearic Islands, Spain, in the second paper. A number of conclusions can be drawn from the findings. For example, integrative reasons for learning the language stood out as a major component of the students' motivation but their integrative orientation had to do with integration and fluent communication with the broad international community as opposed to a valued target language community (Dörnyei, 2009; Papi, 2010). Her study also suggests that there is no longer a clear-cut distinction between integrative and instrumental orientations.

The third paper related to teaching concerns experiential learning on the part of Heritage Learners (HLS) of Spanish in the United States. Diana Ruggiero's work involves community service learning (CSL) and intercultural competence (ICC) on the part of students with previous knowledge of Spanish, the target language of the course, thanks to their cultural heritage and upbringing. To date, according to the author, little has been done to show the relationship of these areas of study and LSP. The project described involved students from the University of Memphis, local non-profit organizations and community members from the linguistically and ethnically diverse neighborhood. The findings revealed that the HLs showed more cultural sensitivity than the non-HLs at the start of the project related to the arts and that their self-confidence and self-esteem increased thanks to the application of their language skills.

In the next article, Jesús García Laborda and Luis Bejarano discuss similarities and differences between courses in Spanish for Specific Purposes in the United States and in English for Specific Purposes in Spain. Their paper discusses the features of the courses including descriptions of the students, the methodology and materials employed, use of the language, assessment and the limits of both teaching processes. They authors conclude that there are more similarities than differences but that additional research is needed in order to establish a common framework for courses in LSP.

The next two papers in this issue discuss linguistic aspects of LSP. Pilar Durán Escribano and Georgina Cuadrado Esclapez discuss metaphor mappings in English in the context of science in the first of them. Their study is based on a research project that led to publication of the Bilingual Dictionary of Scientific and Technical Metaphors and Metonymies. Here they have focused on metaphorical terms from the earth sciences, agronomy and mechanical engineering and found several conceptual 
metaphors that can be described as "humanizing", "organicist" and "objectual" according to the nature of the source domain. The findings suggest that metaphorical reasoning is at the core of creative scientific development and that there is much more to be investigated within the broader scope of science and technology.

The second paper, by Beatriz Burgos and Kerstin Rohr, relates to medical terminology in German and Spanish. Thanks to their Greek and Latin origins, medical terms coming from these languages tend to maintain their semantic value and are still alive. However, in this context, the disambiguation principle does not always apply due to the existence of synonyms and alternatives from the general language and it is complicated to create a homogeneous medical language. The present study examines this situation and also looks at the different processes of word formation, in particular, composition and derivation.

The final paper in this issue continues in the medical field but falls under the area of translation. In her article, Raquel Lázaro Gutiérrez discusses the adaptation of videos aimed at migrants living in Spain and issues involved in their "transcreation" with a view to examining their effectiveness in communicating their content. She provides a description and critical analysis of the collection of videos examined and reports on the views of the different focus groups involved in the study. It was found that some adaptations have been made but more are needed. For example, some of the videos attempt to close the gap between the two cultures by using mother tongue actors that appear to be in natural settings for the target viewers, but the tendency is to consider many of the migrant cultures as members of one group.

It is our sincere desire that these papers will prove to be as stimulating to readers of this issue of the journal as they have been to us and that they will serve to encourage specialists in LSP and in the different fields of study to pursue further research on the promising issues raised here.

\section{References}

Dörnyei, Z. (2009). The L2 motivational self-system. In Z. Dörney \& E. Ushioda (Eds.), Motivation, Language Identity and the L2 Self (pp. 9-42). Clevedon: Multilingual Matters.

Papi, M. (2010). The L2 motivational self system, L2 anxiety, and motivated behaviour: A structural equation modelling approach. System, 38, 467-479. 